\title{
Monitoring the Change of Technological Impacts of Technology Sectors Using Patent Information: the Case of Korea
}

\author{
Janghyeok Yoon, Mujin Kim, Doyeon Kim, Jonghwa Kim* \\ Department of Industrial Engineering, Konkuk University, Seoul, Korea \\ Hyunseok Park \\ Graduate School of Technology and Innovation Management, Pohang University of Science and Technology, \\ Pohang, Korea
}

(Received: October 30, 2014 / Revised: January 6, 2015 / Accepted: January 12, 2015)

\begin{abstract}
A primary concern of national R\&D plans is to encourage technological development in private firms and research institutes. For effective R\&D planning and program support, it is necessary to assess technological impacts that may exist both directly and indirectly among technology areas within the whole technology system; however, previous studies analyze only direct impacts among technologies, failing to capture both direct and indirect impacts. Therefore, this study proposes an approach based on decision-making trial and evaluation laboratory (DEMATEL) to identifying specific characteristics of technology areas, such as technological impact and degree of cause or effect (DCE). The method employs patent co-classification analysis to construct a technological knowledge flow matrix. Next, to capture both direct and indirect effects among technology areas, it incorporates the modified DEMATEL process into patent analysis. The method helps analysts assess the technological impact and DCE of technology areas, and observe their evolving trajectories over time, thereby identifying relevant technological implications. This study presents a case study using Korean patents registered during 2003-2012. We expect our analysis results to be helpful input for R\&D planning, as well as the suggested approach to be incorporated into processes for formulating national R\&D plans.
\end{abstract}

Keywords: Patent Analysis, Technological Impact, Patent Co-Classification, Decision-Making Trial and Evaluation Laboratory(DEMATEL), R\&D Planning

* Corresponding Author, E-mail: jhkim@konkuk.ac.kr

\section{INTRODUCTION}

In the era of global technology competition, technology has become a main growth engine of nations, and firms' competitiveness within a nation is now considered to be a major factor in a nation's competitiveness (Wang et al., 2007). Advances in technology can be beneficial for private firms and for the economy and society at large, and public research and development
(R\&D) policy stimulates and increases firms' innovation activities (Mamuneas and Ishaq Nadiri, 1996; Almus and Czarnitzki, 2003). With this in mind, an important governmental role is to act as a facilitator to encourage and support the technological development of private firms and research institutes (Inzelt, 2004). Therefore, many national governments have tried to foster the development of technology at the national level by developing and deploying a number of different R\&D poli- 
cies and supporting R\&D programs (Garcia and Mohnen, 2010; Huang et al., 2011; Foray et al., 2012).

To formulate effective R\&D plans and to effectively assign limited R\&D funds to government-supported R\&D programs, in particular, dynamic technological trends of the various technology areas that constitute the whole technology system in a nation need to be carefully examined (Park and Yoon, 2013). In doing so, it is necessary to determine the technological impact of or spillover among these technology areas within the whole technology system (Verspagen, 1997; Nomaler and Verspagen, 2008). Such technological impacts should be well assessed because they could be a proxy to estimate the overall technical and scientific effects of investment into a particular technology area (Maurseth and Verspagen, 2002; Ko et al., 2013). In addition, identifying the change in technological impacts over time is necessary for midterm and long-term $R \& D$ investment plans that promote technological development in specific technology areas (Park and Yoon, 2013), such as identification of and investment into original technology areas, applications of technology areas, and emerging technology areas. Therefore, examining the national dynamics of technological impacts over time can provide R\&D planners with significant and meaningful insights.

One approach to identifying the technological impacts of technology areas and their dynamics is to analyze a knowledge network composed of technological knowledge flows (TKFs) among the areas. Usually, such a knowledge network can be constructed using patent data; studies have suggested that patents serve as a prior diagnostic tool for strategic R\&D planning and as a good proxy for generated technological knowledge and knowledge flows (Jafie et al., 2000; Han and Park, 2006). Citations and classification codes in patents are the primary parameters that have been utilized to measure TKFs among technology areas. To date, a number of patent knowledge network-based studies have been suggested to measure inter-industrial knowledge flows (Han and Park, 2006; Park et al., 2009), analyze dynamic patterns of technological convergence and interrelationship in specific technology areas (Li et al., 2007; Lim and Park, 2010; No and Park, 2010; Kim et al., 2013), and identify core and emerging technologies (Lee et al., 2010; Cho and Shih, 2011). As made apparent by these studies, a main concern in analyzing know-ledge networks is to determine the technological impacts among technology areas and their dynamic trends. The quantitative analysis results obtained by these studies provide R\&D planners with the technological characteristics of technology areas within a specific technology network, as well as with technological implications useful for R\&D planning for each technology area.

Despite the contributions of the previous studies, they have some limitations in terms of analyzing the technological impact among technologies. Most of them use direct flows of technological knowledge that can be computed using citations between pairs of patents and co-classifications of patents, neglecting the hidden or indirect knowledge flows (Lee et al., 2009). In addition, the previous studies consider only the importance and coreness of technologies, failing to distinguish between technological impacts by knowledge provision and reception. For valid R\&D planning from a long-term and systemic view, it is necessary to assess technological impacts, which exist both directly and indirectly among various technology areas, as well as to identify the causal characteristics of the areas within the whole technology system.

To remedy the problems, this paper proposes a new patent analysis approach based on the decision-making trial and evaluation laboratory (DEMATEL). To this end, our study first employs patent co-classification analysis to construct a knowledge network for a national technology system. Patent co-classification analysis is a technique to generate a directed TKF network using patent classification codes (Lim and Park, 2010); this paper uses the United States patent classification (USPC) codes. Next, the study quantifies the process of the DEMATEL (Shen et al., 2011), and adopts the modified DEMATEL method not only to capture the comprehensive (both direct and indirect) influences among technology areas within the knowledge network, but also to identify the degree of cause or effect (DCE) with respect to each technology area. Finally, this study helps experts determine evolutionary trajectories of various technology areas in the national technology system from overall and individual viewpoints by mapping the technological impacts and DCEs over time. The working process of the proposed method is illustrated using all Korean patents (a total of $83,519)$ registered during the last decade (2003-2012).

The contribution of this paper is three-fold. First, this study allows analysts to assess the comprehensive technological impacts among technology areas by combining patent co-classification and the modified DEMATEL method. Measuring and using both direct and indirect influences among the areas is contrasted with approaches of previous studies, which mostly used direct influences. Second, this study provides an approach to observe the evolutionary phenomena of these areas over time, and thus, it holds the potential to be applied to any other patent data in order to determine technological impacts and DCEs. Third, this study attempts to identify the dynamic patterns of Korean technology areas from a TKF standpoint, thereby providing an understanding of the technological impacts and DCEs of technology areas in Korea at the national level over the last decade. Therefore, we expect the approach to contribute to the national process of formulating R\&D plans.

\section{THEORETICAL BACKGROUND}

\subsection{Knowledge Flows and Their Measurement in Patent Data}

Patent are considered to be an up-to-date and reli- 
able reflection of technological advances (Yoon and Kim, 2011). Further, a survey reported that patents include more than $90 \%$ of the latest global technical information, and $80 \%$ of the information in patents has not been published in any other form (Park and Yoon, 2013). For these reasons, patent registrations have been widely used as input for a number of methods that determine rapidly evolving technological trends (Yoon and Kim, 2011), formulate technology strategies based on such trends (Lee et al., 2009; Park et al., 2012), and forecast future technological opportunities (Lee et al., 2009; Chen et al., 2011).

A patent represents an invention that has economic and technical value as well as containing all the information about the invention in its several sections, including its bibliographic sections, specifications, and claims. Patent bibliographic information includes various metadata of a patent, including patent numbers, registration dates, applicants, inventors, classification codes, and citations. Among these, the citations and classification codes, in particular, have played a crucial role in constructing TKFs among patents or their technology areas in various studies. The most widely used information to identify TKFs is the patent citation. Studies have used the cited-citing relationships of pairs of patents to construct knowledge flows, assuming patents cited by other later patents include the important ideas upon which the later patents are built (Jafie et al., 2000). Such studies have constructed networks consisting of patents or their technology classifications. However, as mentioned in some studies, patent citations may not work well to represent the most recent patents (Yoon and Park, 2004; Yoon and Kim, 2011). This limitation arises from the citation lag that always exists between a pair of cited and citing patents. One alternative to overcome this limitation is the patent co-classification method (Park and Yoon, 2013). The idea behind patent co-classification analysis is that a relationship between multiple technology classification codes in patents indicates current and potential interactions among technology areas (Lim and Park, 2010). Classification codes of patents are assigned at the date of patent registration. Directed TKFs can be generated by distinguishing the primary classification from supplementary classifications. In the USPC system, in particular, each patent is assigned to one primary class ("invention information") and multiple (0 or more) supplementary classes ("additional information") (Breschi et al., 2003); the direction of TKFs, which can be identified from a patent, is from the primary class to the supplementary classes (Verspagen, 1997).

It is obvious that many recent patents may have had little chance to be cited by later patents (Yoon and Park 2004; Yoon and Kim, 2011). Therefore, the current study employs patent co-classification analysis to measure TKFs from patents and constructs directed TKF matrices among the various technology areas within the whole technology system.

\subsection{Analysis of Technology Networks}

A technology network or matrix using patent citations or patent co-classifications contains TKFs among different technology areas; technology areas are nodes representing the actors within the network, and TKFs among the areas are links that include the direction and extent of the TKFs (Li et al., 2007). Therefore, the use of network analysis methods allows experts to identify the various technological characteristics of the areas. In general, three methods can be employed to analyze the impact of nodes in a network. These methods are social network analysis (SNA), analytic network process (ANP), and DEMATEL.

SNA is a technique to examine the structure of relationships between social entities including groups, organizations, web sites, and scholarly publications (Hanneman and Riddle, 2001). By applying many of the mathematical and statistical measures presented in sociology, SNA has been used to understand the diffusion of innovations, news, and rumors. Among the measures in SNA, centrality measures, such as degree, closeness, and betweenness, can provide significant insights in terms of technological importance. Degree centrality is the local impact of a technology area, closeness centrality describes the overall impact of the area within a network, and betweenness centrality identifies technological intermediaries (Kim et al., 2013; Park and Yoon, 2013). The centrality measures are for use with nodes, while density measures are used for a network or its subnetworks (Haythornthwaite, 1996). Density and cohesion indexes have been used to identify strongly related technology groups and their solidarity and internal interaction (Choi et al., 2011; Yoon and Kim, 2011).

ANP structures a decision problem into a network with a goal, decision criteria, and alternatives (Saaty 2001). Then, it uses a system of pairwise comparisons to measure the weights of the decision factors in a causality network and, finally, to prioritize the alternatives in the decision (Saaty, 2004). Applying ANP to a technology network allows identification of coreness and importance of technology areas within the network (Park and Yoon, 2013). In contrast to SNA, ANP has the advantage that it can be used to consider both direct and indirect impacts for each decision factor (Lee, Kim et al. 2009). However, ANP has some limitations in that it can measure the overall impact of technologies within a technology network but cannot describe the causal relationships among the technology areas, such as the impact of one technology area on other technology areas via knowledge creation or the amount of external technology knowledge a technology area receives via knowledge absorption.

DEMATEL, which was first suggested by Battelle Memorial Institute, is a method to identify the impact and causality among decision factors in a network problem (Gabus and Fontela, 1972; Fontela and Gabus, 1976). SNA does not incorporate direct and indirect impacts 
among decision factors, and ANP does not compute the causal interrelationship among the factors. In contrast, DEMATEL, which is adopted in the current study, is a matrix computation method that captures both the direct and indirect impacts among decision factors. In addition, it can identify the overall impact and the causal relationships among the factors within a network problem (Tseng, 2009). Due to this applicability, DEMATEL has been adopted in a number of studies in various fields in order to choose knowledge management strategies ( $\mathrm{Wu}, 2008$ ), to suggest a perception approach to a cause and effect decision-making model of service quality expectation (Shieh et al., 2010), to identify key success factors of hospital service quality (Tseng, 2009), and to develop management and evaluation models of supplier selection in green supply-chain management (Hsu et al., 2011; Lin, 2011).

Based on a review of network analysis techniques, we concluded that DEMATEL is the most effective approach to address the comprehensive impacts of technology areas and their causal relationships within a national technology system based on TKFs from patents, and therefore, we incorporated DEMATEL into our research methodology.

\section{DATA}

This study aims to identify the impact and interaction among technology areas in a technology network at particular time periods as well as the areas' changing trajectories over time in the national technology system of Korea. To construct a technology network, there are currently several public or commercial patent database services, including KIPRIS (www.kipris.or.kr) and WIPS ON (www.wipson.com), that can be used to retrieve and download patents registered in the United States, Korea, Japan, and European nations. This study uses the USPC codes of patents, and we identified a total of 83,519 patents from KIPRIS, representing Korean applications registered in the United States Patent and Trademark Office (USPTO) patent database from 2003 through 2012. This massive amount of patent data was stored in an electronic Microsoft Excel file for computational analysis. Although some patent classification systems, such as internal patent classification (IPC) and cooperative patent classification (CPC) exist, they could not be used to analyze patent co-classification-based technological knowledge flows for our current patent data; the current IPC system revised in 2006 can have multiple primary technology areas for a patent and the CPC system has been used since 1 January 2013.

We conducted a three-step preprocessing procedure of the collected patents. First, we extracted the technology area information of each patent by preprocessing its bibliographic information. A patent has one or more USPC codes, each of which is represented by a major component called a class and minor components called subclasses. The current USPC system has a total of 473 highest level classes (http://www.uspto.gov/web/patents/ classification/selectnumwithtitle.htm), and each class is represented by three digits. A class differentiates one technology area from the others, and its subclasses describe processes and structural and functional features of the subject encompassed within the scope of the class (Lee et al., 2009). Many previous studies have used the technology class, that is, the first three digits of the USPC, to represent the technology area (Lee et al., 2009; Lim and Park, 2010; No and Park, 2010; Lee et al., 2011); these studies suggest that the first three digits are sufficient to explain the technological discipline related to a patent. For example, consider that a patent has a list of USPC codes 438/726, 333/22R, and 118/723. Then, the most relevant technology areas of the patent are 438 (semiconductor device manufacturing process), 333 (wave transmission lines and networks), and 118 (coating apparatus).

Second, we distinguished primary technology areas from supplementary technology areas. In the USPC system, each patent should be assigned one or more classification codes: one primary USPC code and multiple (0 or more) supplementary USPC codes. The primary USPC code represents a technology class for the claimed knowledge ("invention information") of its patent, and the supplementary class is a relevant technology class for the non-appropriable knowledge ("additional information") (Breschi et al., 2003). Each of the patents that we downloaded has a list of USPC codes with which the patent can be classified, and the USPC code that appears first on the list is the patent's primary USPC code. Separation of a primary USPC code from supplementary USPC codes is an initial input to measure directed TFKs between technology areas through patent co-classification analysis.

Third, we reorganized the patent information according to time period, taking into consideration technological characteristics during each period and their evolutionary trajectories over time. To this end, we divided the whole sample of patents into five groups: 2003-2004, 2005-2006, 2007-2008, 2009-2010, and 2011-2012 in order to observe the technological impacts and DCEs of the technology areas within the overall technology system of Korea.

\section{METHODOLOGY}

\subsection{Patent Co-Classification Analysis}

This study uses patent co-classification analysis to identify TKFs among technology entities using patent classification codes. It has been posited that patent coclassification information does not generate directed TKFs, but directed TKFs can be generated by distinguishing the primary class from the supplementary classes (Lim 


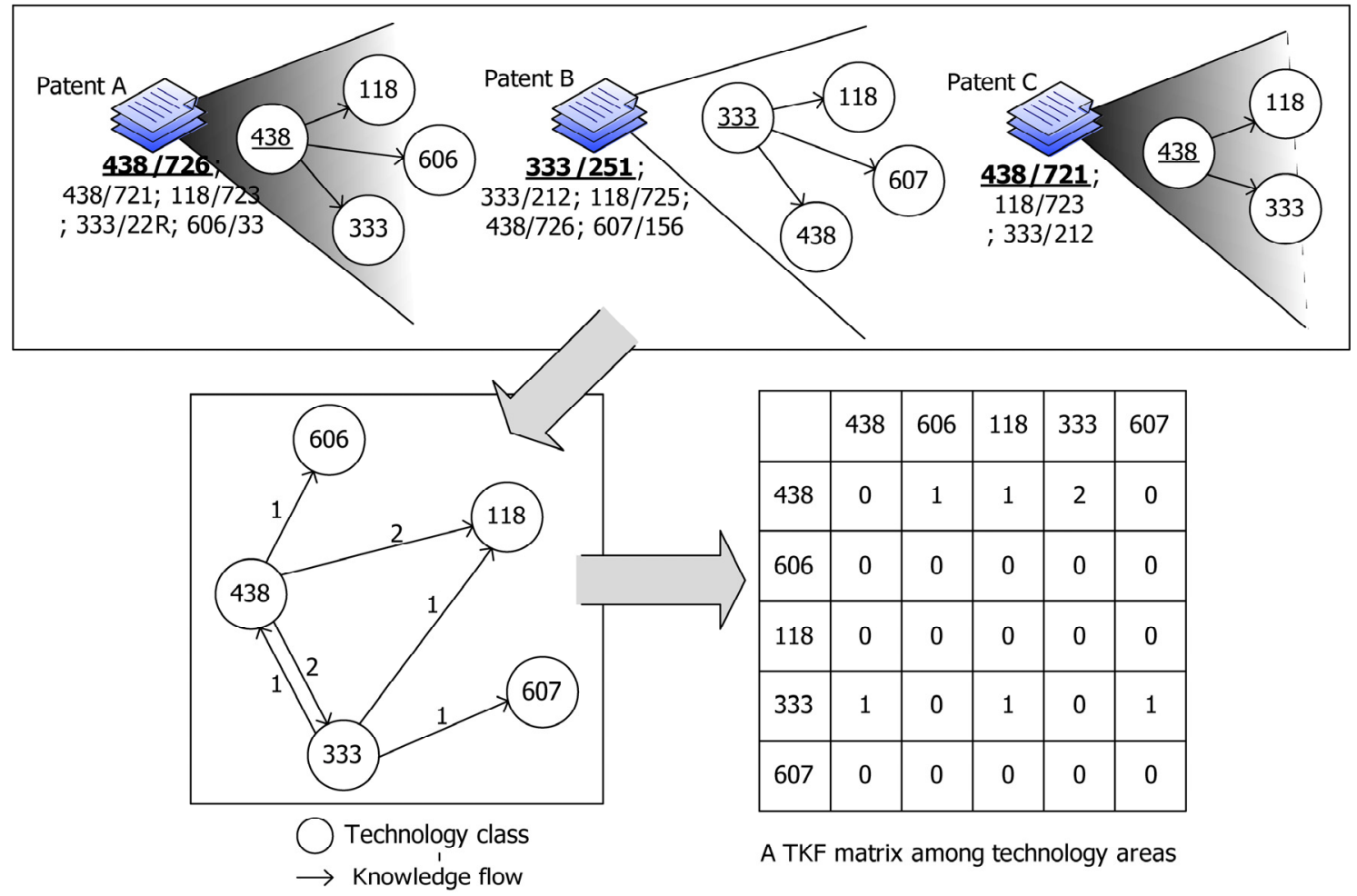

Figure 1. Generation of directed TKF matrices by PCA.

and Park, 2010). Patent co-classification analysis considers the primary class as the knowledge-generating class and the supplementary classes as the knowledgereceiving classes (Lim and Park, 2010). For example (Figure 1), consider that the USPC codes of patent A are 438/726, 438/721, 118/723, 333/22R, and 606/331, and its primary USPC code is $438 / 726$. Patent co-classification analysis outputs a total of four flows among the detailed technology areas: $438 / 726$ to $438 / 721,438 / 726$ to $118 / 723,438 / 726$ to $333 / 22 \mathrm{R}$, and $438 / 726$ to $606 /$ 331. Then, these flows can be converted into the flows 438 to 118,438 to 333 , and 438 to 606 to identify the TKFs among the different technology classes (areas); internal flows within the same technology class are ignored here in order to focus on the interactional impacts and patterns among different technology areas.

By aggregating the TKFs for all patents collected for each period, patent co-classification analysis outputs TKF matrices, which include TKFs among the different technology areas for the five time periods. Each matrix represents a directed network, so various network analysis techniques can be used to identify technological implications, including the impacts of technology areas and the interrelationships among them. However, as mentioned, the TKF matrix currently has some limitations in that it contains only the direct influences among technology areas and does not consider indirect influences. Therefore, this paper employs the DEMATEL method to identify both the direct and indirect influences among technology areas in the TKF matrix.

\subsection{Modified DEMATEL Method}

In a multiple decision-making problem, related decision factors generally construct a very complex relationship network, so it is a difficult task for decision makers to determine the effect of each factor or how it is affected by others (Fontela and Gabus, 1976). In this case, DEMATEL helps to measure the impacts of the factors and the causal relationships among them and to prioritize the factors. Building on the customary DEMATEL (Wu, 2008; Shieh et al., 2010; Hsu et al., 2011; Lin, 2011), this study presents a modified DEMATEL process that uses the TKF matrices obtained via patent co-classification analysis.

\section{Step 1: Generate an initial direct-relation matrix (DRM) for each time period.}

In the customary DEMATEL, given $n$ decision criteria, experts are asked to evaluate the degree of direct influence of factor $i$ on factor $j$ using an integer score ranging from "no influence (0)" to "very high influence (3)" and then, by aggregating the experts" pairwise comparisons, to provide an initial (or average) DRM $Z_{k}$ for period $k$ ( $k$ $=1,2,3,4$, and 5) in an $n \times n$ matrix, in which $z_{i j, \mathrm{k}}$ is the degree to which criteria $i$ affects criteria $j$. DEMATEL addresses the impacts among the decision criteria, so all diagonal elements of $Z$ are set to 0 . In this study, we do not need to aggregate expert evaluations. Instead, we 
use the TKF matrix, which is identified for each time period by patent co-classification analysis, as the initial DRM. A previous DEMATEL-based study using patent citations suggested this quantification process, which divides TKFs by the number of citations into four equal quartiles ( 0 to 3 integer score) by reorganizing the TKFs among industry sectors in descending order (Jeong et al., 2012). For example, the top $25 \%$ of TKFs are scored 3 , and those in the next quartile, $25 \%$ to $50 \%$, of TKFs are scored 2. Although the transformation of TKFs into four integer scores is compatible with the process of DEMATEL, it causes some information loss. In contrast, our approach preserves information about the number of TKFs within individual technology areas by normalizing the TKF matrix for each time period using the same normalization value (Step 2).

Step 2: Calculate a normalized DRM for each time period.

In the customary approach, normalized DRM $X_{k}$ for each period $k$, where the sum of each row and each column is less than 1, can be obtained using Eqs. (1) and (2).

$$
\begin{aligned}
& S_{k}=\min \left[\frac{1}{\max _{i} \sum_{j=1}^{n} z_{i j, k}}, \frac{1}{\max _{j} \sum_{i=1}^{n} z_{i j, k}}\right] \\
& X_{k}=s_{k} \cdot Z_{k}
\end{aligned}
$$

However, to capture the dynamic features of technology areas, this paper needs to compare analysis results by DEMATEL over a total of five time periods. The customary Eqs. (1) and (2) for normalized DRMs compute different normalization values $s_{k}$ for $Z_{k}$ for each time period, so the DEMATEL results using them are obviously relative. Therefore, the two equations for normalized DRMs require some modification for our purposes. We normalize an initial DRM $Z_{k}$ for period $k$ with the minimum normalization value $s$ obtained using Eqs. (3) and (4). Then, it is possible to conduct comparisons among the DEMATEL analysis results during each time period.

$$
\begin{aligned}
& s^{*}=\min \left(s_{k}\right) \\
& X_{k}=s^{*} \cdot Z_{k}
\end{aligned}
$$

\section{Step 3: Compute a total relation matrix (TRM) for each time period.}

Because there is a continuous decrease in the indirect effects along the powers of the normalized DRM $X_{k}$, the TRM $T_{k}$ for time period $k$ including both direct and indirect influences among the decision criteria can be identified from the convergent solution of the power series of $X_{k}$ according to Eqs. (4) and (5). Element $t_{i j, \mathrm{k}}$ of $T_{k}$ is the degree of the total effect of criteria $i$ on factor $j$, both directly and indirectly. Then, we can obtain $C\left(c_{i, k}\right)$, which is the total effect, both direct and indirect, of factor $i$ on all other factors, and $R\left(r_{i, k}\right)$, which is the total effect of all other factors on factor $i$ (Eqs. (6) and (7)). Therefore, the value of $C+R$ is the degree of impact of factor $i$ on the whole network, and the value of $C-R$ indicates the net effect of factor $i$; a negative value for the difference implies that factor $i$ is a net receiver within a network in terms of technological impact, while a positive value indicates factor $i$ is a net impact producer. The value of $C+R$ represents the total impact of a technology area on other technology areas in a technology network, so this paper considers $C+R$ to be the technological impact of the technology area. Likewise, the value of $C-R$ shows whether a technology area acts as a knowledge producer or receiver, so we use $C-R$ as the DCE of the technology.

$$
\begin{gathered}
\left(I-X_{k}\right)^{-1}=\lim _{m \rightarrow \infty}\left(I+X_{k}+X_{k}^{2}+X_{K}^{3}+\cdots+X_{k}^{m}\right) \\
T_{k}=\left[t_{i j}\right]_{k}=X_{k}+X_{k}^{2}+X_{k}^{3}+\cdots+X_{k}^{m}=X_{k}\left(I-X_{k}\right)^{-1} \\
C=c_{i, k}=\sum_{j=1}^{n} t_{i j, k} \\
R=r_{i, k}=\sum_{j=1}^{n} t_{i j, k}
\end{gathered}
$$

\section{RESULTS}

\subsection{Descriptive statistical analyses}

The total number of patents submitted by Korean applicants in the USPTO database was 83,518 from 2003 through 2012, and the rate of increase for the five periods was $35.88 \%$ (Table 1). Patent registrations numbered 8,039 (9.63\%) for period 2003-2004, 9,976 (11.94\%) for period 2005-2006, 15,956 (19.10\%) for period 2007-2008, 22,141 (26.51\%) for period 20092010 , and 27,406 (32.81\%) for period 2011-2012. This distribution shows that the number of patent registrations increased rapidly during the study period, and in particular, intellectual property produced by technological development in Korea dramatically increased over the last two periods, 2009-2010 and 2011-2012 (59.32\%).

Table 1. Trend of patent registration

\begin{tabular}{ccc}
\hline Year & $\begin{array}{c}\text { \# of patents } \\
\text { registered }\end{array}$ & $\begin{array}{c}\% \text { of total patents registered } \\
\text { in the study period }\end{array}$ \\
\hline $2003-2004$ & 8,039 & $9.63 \%$ \\
\hline $2005-2006$ & 9,976 & $11.94 \%$ \\
\hline $2007-2008$ & 15,956 & $19.10 \%$ \\
\hline $2009-2010$ & 22,141 & $26.51 \%$ \\
\hline $2011-2012$ & 27,406 & $32.81 \%$ \\
\hline Total & 83,518 & $100.00 \%$ \\
\hline Average & 16,704 & - \\
\hline Rate of increase & $35.88 \%$ & - \\
\hline
\end{tabular}


For each of the 473 technology classes, TKF creation and reception were identified using the results of patent co-classification analysis (Table 2); these results show only the amount of direct TKF creation and reception, but they help provide an overall understanding of the characteristics of technology areas in terms of technological knowledge creation and reception. The top 30 technology areas created $64,990(68.888 \%)$ of the total 94.343 TKF creations during the last ten years, while the other technology areas created 29,353 (31.112\%) of the total TKF creations. This illustrates that only a small portion $(8.5 \%)$ of all technology areas contributed to the total TKF creation, and thus, the practical output regard- ing technological development in Korea was highly skewed toward those technology areas. In particular, U438 (semiconductor device manufacturing: process) had a unique position in TKF creation (18,595 TKFs; $19.710 \%)$, and this statistic explains that semiconductor technology is a leading-edge technology that has greatly and actively influenced other technology areas, driving technological advances in Korea over the last decade. U257 (active solid-state devices, e.g., transistors, solid-state diodes), U455 (telecommunications), U370 (multiplex communications), and U345 (computer graphics processing and selective visual display systems) were ranked second $(4,716 \mathrm{TKFs} ; 5.00 \%)$, third $(4,619 \mathrm{TKFs} ; 4.90 \%)$, fourth

Table 2. Trends in technological knowledge creation and reception by technology class (top 30)

\begin{tabular}{|c|c|c|c|c|c|c|c|}
\hline \multicolumn{4}{|c|}{ Technological knowledge flow creation $\left(\mathrm{TKF}_{\mathrm{C}}\right)$} & \multicolumn{4}{|c|}{ Technological knowledge flow reception $\left(\mathrm{TKF}_{\mathrm{R}}\right)$} \\
\hline USPC & Rank & $\#$ of $\mathrm{TKF}_{\mathrm{C}}$ & $\%$ of $\mathrm{TKF}_{\mathrm{C}}$ & USPC & Rank & $\#$ of $\mathrm{TKF}_{\mathrm{R}}$ & $\%$ of $\mathrm{TKF}_{\mathrm{R}}$ \\
\hline U438 & 1 & 18,595 & $19.71 \%$ & U257 & 1 & 20,122 & $21.33 \%$ \\
\hline U257 & 2 & 4,716 & $5.00 \%$ & $\mathrm{U} 438$ & 2 & 4,199 & $4.45 \%$ \\
\hline $\mathrm{U} 455$ & 3 & 4,619 & $4.90 \%$ & U455 & 3 & 4,009 & $4.25 \%$ \\
\hline U370 & 4 & 4,376 & $4.64 \%$ & U370 & 4 & 3,209 & $3.40 \%$ \\
\hline U345 & 5 & 3,016 & $3.20 \%$ & U348 & 5 & 2,975 & $3.15 \%$ \\
\hline U375 & 6 & 2,803 & $2.97 \%$ & U375 & 6 & 2,505 & $2.66 \%$ \\
\hline U428 & 7 & 2,484 & $2.63 \%$ & U345 & 7 & 1,817 & $1.93 \%$ \\
\hline U369 & 8 & 2,133 & $2.26 \%$ & U349 & 8 & 1,722 & $1.83 \%$ \\
\hline U349 & 9 & 1,904 & $2.02 \%$ & U313 & 9 & 1,448 & $1.54 \%$ \\
\hline U382 & 10 & 1,636 & $1.73 \%$ & U382 & 10 & 1,144 & $1.21 \%$ \\
\hline U313 & 11 & 1,483 & $1.57 \%$ & U709 & 11 & 1,034 & $1.10 \%$ \\
\hline $\mathrm{U} 430$ & 12 & 1,367 & $1.45 \%$ & U365 & 12 & 1,027 & $1.09 \%$ \\
\hline U361 & 13 & 1,344 & $1.43 \%$ & U361 & 13 & 1,002 & $1.06 \%$ \\
\hline U348 & 14 & 1,107 & $1.17 \%$ & U977 & 14 & 965 & $1.02 \%$ \\
\hline U252 & 15 & 1,083 & $1.15 \%$ & U428 & 15 & 867 & $0.92 \%$ \\
\hline U365 & 16 & 1,028 & $1.09 \%$ & U327 & 16 & 864 & $0.92 \%$ \\
\hline U029 & 17 & 993 & $1.05 \%$ & U315 & 17 & 857 & $0.91 \%$ \\
\hline U713 & 18 & 980 & $1.04 \%$ & U714 & 18 & 852 & $0.90 \%$ \\
\hline U714 & 19 & 973 & $1.03 \%$ & U359 & 19 & 849 & $0.90 \%$ \\
\hline U386 & 20 & 960 & $1.02 \%$ & U427 & 20 & 806 & $0.85 \%$ \\
\hline U429 & 21 & 869 & $0.92 \%$ & U362 & 21 & 768 & $0.81 \%$ \\
\hline U359 & 22 & 848 & $0.90 \%$ & U379 & 22 & 740 & $0.78 \%$ \\
\hline U514 & 23 & 767 & $0.81 \%$ & U713 & 23 & 725 & $0.77 \%$ \\
\hline U219 & 24 & 738 & $0.78 \%$ & $\mathrm{U} 252$ & 24 & 700 & $0.74 \%$ \\
\hline $\mathrm{U} 250$ & 25 & 731 & $0.78 \%$ & U340 & 25 & 649 & $0.69 \%$ \\
\hline U701 & 26 & 725 & $0.77 \%$ & $\mathrm{U} 435$ & 26 & 641 & $0.68 \%$ \\
\hline U360 & 27 & 695 & $0.74 \%$ & U707 & 27 & 640 & $0.68 \%$ \\
\hline U709 & 28 & 684 & $0.73 \%$ & U725 & 28 & 618 & $0.66 \%$ \\
\hline U700 & 29 & 676 & $0.72 \%$ & $\mathrm{U} 430$ & 29 & 611 & $0.65 \%$ \\
\hline $\mathrm{U} 435$ & 30 & 657 & $0.70 \%$ & U526 & 30 & 561 & $0.59 \%$ \\
\hline \multicolumn{2}{|c|}{ Subtotal of top 30} & 64,990 & $68.89 \%$ & \multicolumn{2}{|c|}{ Subtotal of top 30} & 58,365 & $61.86 \%$ \\
\hline \multicolumn{2}{|c|}{ Others } & 29,353 & $31.11 \%$ & \multicolumn{2}{|c|}{ Others } & 35,978 & $38.14 \%$ \\
\hline \multicolumn{2}{|c|}{ Total } & 94,343 & $100.00 \%$ & \multicolumn{2}{|c|}{ Total } & 94,343 & $100.00 \%$ \\
\hline
\end{tabular}


(4,376 TKFs; 4.64\%), and fifth (3,016 TKFs; $3.20 \%)$, respectively. U257 is a device memory technology that has a strong relationship with semiconductor process technology U438. U455 and U370 are specific types of communication technology in Internet and mobile products. U345 is a graphic and display technology, and it is a component technology area for mobile devices and smart TVs and monitors. These results show that Korea's top-ranked technology areas, which are high-technology industries including semiconductor, communication, mobile, and display technologies, have a distinguished impact on other technology areas in an overall sense.

Regarding TKF reception, the top 30 technology areas received 58,369 (61.86\%) of the total 94,343 TKF receptions, while other technology areas received 35,978 TKFs (38.14\%). This means that a small portion of the technology areas in Korea, similar to the TKF creation statistics, greatly contributed to the exploitation of created technological knowledge. In particular, U257 was top-ranked and received 20,122 TKFs (21.33\%). Considering the TKF reception of U257 is about 4.27 times larger than its TKF creation, it is a dominant application area that actively exploits technological knowledge from external sources; in fact, transistors and solid-state devices have strong relationships with technology areas in semiconductor, mobile, and display industries. U438, ranked second in TKF reception, was considered to be an original technology area because it primarily diffuses much technological knowledge to external recipients; U438 diffuses (18,595 TKFs) about 4.43 times more TKFs than it receives (4,199 TKFs). U455, U370, and U348 (television) were ranked third (4,009 TKFs; $4.25 \%$ ), fourth $(3,209$ TKFs; $3.40 \%)$, and fifth $(2,975$ TKFs; $3.15 \%$ ), respectively, with regard to TKF reception. Among them, U455 and U370 seemed to be active in both TKF creation and reception. However, the TKF reception of U348 was about 2.69 times more active than its TKF creation (1,107 TKFs). This implies that U347 is a dominant application area in Korea; in fact, recent television technology including smart TVs is the result of integrating communication, graphic processing, and display technologies.

\subsection{Analyses of Technological Impact and Degree of Cause or Effect}

By applying DEMATEL to the direct TKF matrix, the technological impact and DCE for each technology area were computed. As mentioned in Section 4.2, the purpose of our study requires comparing the dynamic trends of technological impacts and DCEs of technology areas over time. Therefore, our study modified the process of DEMATEL by using an identical normalization value $s^{*}$ for all time periods. According to the results of patent co-classification analysis, the $1 / s_{k}$ values for the different time periods $(k=1,2,3,4$, and 5) were found to be 3,062 for period 2003-2004, 3,515 for period
2005-2006, 5,494 for period 2007-2008, 4,172 for period 2009-2010, and 3,879 for period 2011-2012. Therefore, we set the normalization value $s^{*}$ to $1 / 5,494$ (= 0.000182) using Eq. (3). We applied this value to the DEMATEL method for the five time periods, thereby producing five TRMs that encompass the major technological impacts of the technology areas in the Korean technology system.

First of all, the technological impact of each technology area was calculated using Eqs. (5) and (6) (Table $3)$. Overall, the total sums of the technological impacts have increased steadily over time (from 6.240 in period 2003-2004 to 16.479 in period 2011-2012). This is generally expected and can be explained by the increase in patent registrations over time; the larger the number of patents registered, the greater is the likelihood of TKFs. The subtotal of technological impacts of the top 30 technology areas increased from $63.79 \%$ to $70.67 \%$, while the sum of technological impacts of all other areas decreased from $36.21 \%$ to $29.33 \%$. These relative trends show that the impact of technological knowledge in Korea during the studied time period was highly concentrated in specific technology areas, and conversely, the technological impacts of other areas weakened over time. Similar to the analysis of technological knowledge creation and reception (Table 2), the technological impact of U257 was ranked first for all time periods, but its increasing trend was slow because of its initial extremely high technological impact. Some technology areas showed dramatic increases in technological impact, including U455, U370, U709 (computers and digital processing systems: multicomputer data transferring), U713 (computers and digital processing systems: support), and U725 (interactive video distribution systems). In particular, the initial technological impact values of U455 (rate of increase $=0.890)$ and U370 (rate of increase $=$ 0.816 ) were 0.092 and 0.100 , respectively, but increased to 1.175 and 1.085 . This indicates that many Korean firms and research institutes have focused on the development of communication technologies. This may be related to the trend that many Korean companies, including Samsung and LG, have recently been establishing a strong position in the mobile and network industries. The technological impacts of U709 (rate of increase $=0.782$ ) and U713 (rate of increase $=0.728$ ) have rapidly increased. These two technology areas are strongly related to network data transferring and its infrastructure, and the rapid increases in their technological impacts illustrate Korea's recent advances in network data transferring, mobile network interconnecting, and data security.

Next, the DCEs of technology areas were computed using Eqs. (6) and (7) (Table 4). Technological impact is the total influence considering both created and received influences among technology areas, while DCE represents the net influence. A technology area is a net producer (original technology) within a technology network if its DCE has a positive value, while that with 
Yoon, Kim, Kim, Kim, and Park: Industrial Engineering \& Management Systems

Vol 14, No 1, March 2015, pp.58-72, (C) 2015 KIIE

66

Table 3. Technological impacts $(\mathrm{C}+\mathrm{R})$ of the top 30 technology areas

\begin{tabular}{|c|c|c|c|c|c|c|c|c|c|c|c|c|c|c|}
\hline \multirow[t]{2}{*}{ USPC } & \multicolumn{2}{|c|}{$\begin{array}{c}\text { Period } \\
2003-2004\end{array}$} & \multicolumn{2}{|c|}{$\begin{array}{c}\text { Period } \\
2005-2006 \\
\end{array}$} & \multicolumn{2}{|c|}{$\begin{array}{c}\text { Period } \\
2007-2008\end{array}$} & \multicolumn{2}{|c|}{$\begin{array}{c}\text { Period } \\
2009-2010\end{array}$} & \multicolumn{2}{|c|}{$\begin{array}{c}\text { Period } \\
2011-2012 \\
\end{array}$} & \multirow{2}{*}{$\begin{array}{l}\text { Total } \\
\mathrm{C}+\mathrm{R}\end{array}$} & \multirow{2}{*}{$\begin{array}{l}\% \text { of } \\
\text { Total } \\
\mathrm{C}+\mathrm{R}\end{array}$} & \multirow{2}{*}{$\begin{array}{l}\text { Aver- } \\
\text { age }\end{array}$} & \multirow{2}{*}{$\begin{array}{l}\text { Rate of } \\
\text { increase }\end{array}$} \\
\hline & $\mathrm{C}+\mathrm{R}$ & $\%$ & $\mathrm{C}+\mathrm{R}$ & $\%$ & $\mathrm{C}+\mathrm{R}$ & $\%$ & $\mathrm{C}+\mathrm{R}$ & $\%$ & $\mathrm{C}+\mathrm{R}$ & $\%$ & & & & \\
\hline U257 & 1.341 & $21.50 \%$ & 1.319 & $20.12 \%$ & 1.361 & $18.17 \%$ & 1.966 & $17.71 \%$ & 2.327 & $14.12 \%$ & 8.315 & $17.37 \%$ & 1.663 & 0.148 \\
\hline U438 & 0.844 & $13.52 \%$ & 0.867 & $13.22 \%$ & 1.270 & $16.96 \%$ & 1.610 & $14.50 \%$ & 1.908 & 11.58 & 9 & 13.5 & 0 & 6 \\
\hline U455 & 0.092 & $1.48 \%$ & 0.147 & $2.24 \%$ & 0.276 & $3.68 \%$ & 0.545 & $4.91 \%$ & 1.175 & $7.13 \%$ & 2.235 & $4.67 \%$ & 0.447 & 0.890 \\
\hline U370 & 0.100 & $1.60 \%$ & 0.127 & $1.93 \%$ & 0.228 & $3.04 \%$ & 0.472 & $4.25 \%$ & 1.085 & $6.58 \%$ & 2.011 & $4.20 \%$ & 0.402 & 0.816 \\
\hline U375 & 0.150 & $2.41 \%$ & 0.181 & $2.76 \%$ & 0.197 & $2.63 \%$ & 0.276 & $2.49 \%$ & 0.530 & $3.22 \%$ & 1.334 & $2.79 \%$ & 0.267 & 0.370 \\
\hline U345 & 0.094 & $1.51 \%$ & 0.136 & $2.07 \%$ & 0.176 & $2.35 \%$ & 0.252 & $2.27 \%$ & 0.454 & $2.76 \%$ & 1.113 & $2.32 \%$ & 0.223 & 0.482 \\
\hline U348 & 0.163 & $2.61 \%$ & 0.197 & $3.00 \%$ & 0.180 & $2.40 \%$ & 0.178 & $1.60 \%$ & 0.326 & $1.98 \%$ & 1.043 & $2.18 \%$ & 0.209 & 0.189 \\
\hline U349 & 0.095 & $1.52 \%$ & 0.147 & $2.24 \%$ & 0.143 & $1.90 \%$ & 0.269 & $2.43 \%$ & 0.355 & $2.16 \%$ & 1.009 & $2.11 \%$ & 0.202 & 0.392 \\
\hline U313 & 0.089 & $1.42 \%$ & 0.080 & $1.22 \%$ & 0.106 & $1.42 \%$ & 0.207 & $1.87 \%$ & 0.272 & $1.65 \%$ & 0.754 & $1.58 \%$ & 0.151 & 0.324 \\
\hline U428 & 0.084 & $1.34 \%$ & 0.077 & $1.18 \%$ & 0.113 & $1.51 \%$ & 0.200 & $1.80 \%$ & 0.264 & $1.60 \%$ & 0.738 & $1.54 \%$ & ( & 0.333 \\
\hline U382 & 0.063 & $1.01 \%$ & 0.079 & $1.20 \%$ & 0.122 & $1.63 \%$ & 0.135 & $1.22 \%$ & 0.245 & $1.49 \%$ & 0.644 & $1.35 \%$ & 0.129 & 0.403 \\
\hline U365 & 0.053 & $0.86 \%$ & 0.092 & $1.40 \%$ & 0.090 & $1.20 \%$ & 0.151 & $1.36 \%$ & 0.209 & $1.27 \%$ & 4 & $1.24 \%$ & 0.119 & .406 \\
\hline U361 & 0.067 & $1.07 \%$ & 0.071 & $1.08 \%$ & 0.114 & $1.52 \%$ & 0.133 & $1.20 \%$ & 0.198 & $1.20 \%$ & 0.583 & $1.22 \%$ & 0.117 & 0.312 \\
\hline U369 & 0.120 & $1.93 \%$ & 0.125 & $1.91 \%$ & 0.196 & $2.62 \%$ & 0.043 & $0.39 \%$ & 0.028 & $0.17 \%$ & 0.513 & $1.07 \%$ & 0.103 & -0.305 \\
\hline U709 & 0.022 & $0.36 \%$ & 0.033 & $0.51 \%$ & 0.045 & $0.60 \%$ & 0.134 & $1.20 \%$ & 0.224 & $1.36 \%$ & 0.458 & $0.96 \%$ & 0.092 & 0.782 \\
\hline U430 & 0.098 & $1.58 \%$ & 0.070 & $1.07 \%$ & 0.075 & $1.00 \%$ & 0.095 & $0.86 \%$ & 0.107 & $0.65 \%$ & 0.446 & $0.93 \%$ & 0.089 & 0.022 \\
\hline U714 & 0.040 & $0.64 \%$ & 0.065 & $0.98 \%$ & 0.077 & $1.02 \%$ & 0.102 & $0.92 \%$ & 0.155 & $0.94 \%$ & 0.438 & $0.92 \%$ & 0.088 & 0.402 \\
\hline U252 & 0.033 & $0.53 \%$ & 0.034 & $0.52 \%$ & 0.042 & $0.56 \%$ & 0.091 & $0.82 \%$ & 0.210 & $1.27 \%$ & 0.410 & $0.86 \%$ & 0.082 & 0.584 \\
\hline U359 & 0.054 & $0.86 \%$ & 0.063 & $0.96 \%$ & 0.081 & $1.07 \%$ & 0.092 & $0.83 \%$ & 0.103 & $0.63 \%$ & 0.393 & $0.82 \%$ & 0.079 & 0.178 \\
\hline U713 & 0.024 & $0.38 \%$ & 0.028 & $0.42 \%$ & 0.043 & $0.58 \%$ & 0.083 & $0.75 \%$ & 0.212 & $1.29 \%$ & 0.390 & $0.81 \%$ & 0.078 & 0.728 \\
\hline U977 & 0.036 & $0.58 \%$ & 0.024 & $0.36 \%$ & 2 & $0.29 \%$ & 0.106 & $0.95 \%$ & 0.174 & $1.06 \%$ & 0.362 & $0.76 \%$ & 0.072 & 0.481 \\
\hline U315 & 0.063 & $1.01 \%$ & 0.057 & $0.88 \%$ & 0.059 & $0.79 \%$ & 0.080 & $0.72 \%$ & 0.102 & $0.62 \%$ & 0.361 & $0.75 \%$ & 0.072 & 0.129 \\
\hline U362 & 0.016 & $0.25 \%$ & 0.038 & $0.58 \%$ & 0.043 & $0.58 \%$ & 0.107 & $0.96 \%$ & 0.136 & $0.83 \%$ & 0.340 & $0.71 \%$ & 0.068 & 0.717 \\
\hline U427 & 0.077 & $1.23 \%$ & 0.035 & $0.54 \%$ & 0.046 & $0.61 \%$ & 0.071 & $0.64 \%$ & 0.109 & $0.66 \%$ & 0.339 & $0.71 \%$ & 0.068 & 0.092 \\
\hline U327 & 0.025 & $0.40 \%$ & 0.048 & $0.73 \%$ & 0.049 & $0.65 \%$ & 0.101 & $0.91 \%$ & 0.098 & $0.59 \%$ & 0.321 & $0.67 \%$ & 0.064 & 0.412 \\
\hline U725 & 0.007 & $0.12 \%$ & 0.024 & $0.36 \%$ & 0.030 & $0.40 \%$ & 0.074 & $0.66 \%$ & 0.181 & $1.10 \%$ & 15 & $0.66 \%$ & 0.063 & 1.218 \\
\hline U029 & 0.048 & $0.77 \%$ & 0.063 & $0.96 \%$ & 0.048 & $0.65 \%$ & 0.062 & $0.56 \%$ & 0.084 & $0.51 \%$ & 0.306 & $0.64 \%$ & 0.061 & 0.150 \\
\hline U340 & 0.025 & $0.39 \%$ & 0.037 & $0.56 \%$ & 0.035 & $0.46 \%$ & 0.080 & $0.72 \%$ & 0.127 & $0.77 \%$ & 0.303 & $0.63 \%$ & 0.061 & 0.508 \\
\hline U379 & 0.029 & $0.47 \%$ & 0.042 & $0.64 \%$ & 0.034 & $0.45 \%$ & 0.065 & $0.59 \%$ & 0.117 & $0.71 \%$ & 0.288 & $0.60 \%$ & 0.058 & 0.413 \\
\hline U429 & 0.027 & $0.44 \%$ & 0.023 & $0.35 \%$ & 0.022 & $0.29 \%$ & 0.086 & $0.77 \%$ & 0.129 & $0.78 \%$ & 0.287 & $0.60 \%$ & 0.057 & 0.473 \\
\hline Subtotal & 3.980 & $63.79 \%$ & 4.327 & $65.98 \%$ & 5.321 & $71.04 \%$ & 7.868 & $70.86 \%$ & 11.646 & $70.67 \%$ & 33.143 & $69.23 \%$ & - & - \\
\hline Others & 2.260 & $36.21 \%$ & 2.231 & $34.02 \%$ & 2.169 & $28.96 \%$ & 3.235 & $29.14 \%$ & 4.833 & $29.33 \%$ & 14.728 & $30.77 \%$ & - & - \\
\hline $\begin{array}{l}\text { Total } \\
\text { sum }\end{array}$ & 6.240 & $100.00 \%$ & 6.558 & $100.00 \%$ & 7.490 & $100.00 \%$ & 11.104 & $100.00 \%$ & 16.479 & $100.00 \%$ & 47.871 & $100.00 \%$ & - & - \\
\hline
\end{tabular}

a negative DCE is considered to be a net receiver (application technology). Among the top 30 technology areas with positive DCEs, U438 had the highest DCE value. Tracing the change in U438's DCE values (rate of increase $=-0.45$ ) over time, we see that the area mostly provided its technological knowledge to external recipients until the period 2007-2008, after which the area's tendency changed to be more balanced between receiv- ing technological knowledge from external sources and providing knowledge to others. This shows that U438 primarily played a role of knowledge diffuser, an initial original technology that becomes active in both knowledge creation and reception. Interestingly, many of the top 30 technology areas with negative DCE values have gradually changed to receive technological knowledge from external sources over time; 15 technology areas 
Monitoring the Change of Technological Impacts of Technology Sectors Using Patent Information

Vol 14, No 1, March 2015, pp.58-72, (C) 2015 KIIE

Table 4. Technological cause and effect degrees (C-R) of the top 30 technology areas

\begin{tabular}{|c|c|c|c|c|c|c|c|c|c|c|c|c|c|c|c|c|c|}
\hline \multirow[t]{2}{*}{ USPC } & $\begin{array}{r}2003 \\
-2004 \\
\end{array}$ & $\begin{array}{c}2005 \\
-2006 \\
\end{array}$ & $\begin{array}{c}2007 \\
-2008 \\
\end{array}$ & $\begin{array}{c}2009 \\
-2010 \\
\end{array}$ & $\begin{array}{c}2011 \\
-2012 \\
\end{array}$ & \multirow{2}{*}{$\begin{array}{c}\text { Total } \\
\text { C-R } \\
\text { (Positive) }\end{array}$} & \multirow[t]{2}{*}{ Average } & \multirow[t]{2}{*}{$\begin{array}{l}\text { Inc. } \\
\text { rate }\end{array}$} & \multirow[t]{2}{*}{ USPC } & $\begin{array}{r}2003 \\
-2004 \\
\end{array}$ & $\begin{array}{c}2005 \\
-2006 \\
\end{array}$ & $\begin{array}{c}2007 \\
-2008 \\
\end{array}$ & $\begin{array}{c}2009 \\
-2010 \\
\end{array}$ & $\begin{array}{c}2011 \\
-2012 \\
\end{array}$ & \multirow{2}{*}{$\begin{array}{c}\text { Total } \\
\text { C-R } \\
\text { (Negative) }\end{array}$} & \multirow[t]{2}{*}{ Average } & \multirow{2}{*}{$\begin{array}{l}\text { Inc. } \\
\text { rate }\end{array}$} \\
\hline & C-R & C-R & C-R & C-R & C-R & & & & & C-R & C-R & C-R & C-R & C-R & & & \\
\hline U438 & 0.328 & 0.419 & 0.885 & 0.365 & 0.030 & 2.026 & 105 & 45 & 257 & -1.121 & -1.072 & -0.981 & -1.127 & -1.250 & .552 & -1.110 & 0.03 \\
\hline U369 & 0.067 & 0.069 & 0.159 & .020 & -0.009 & 0.266 & 53 & - & U348 & -0.116 & -0.131 & -0.105 & -0.093 & -0.153 & -0.599 & 120 & 0.07 \\
\hline $\mathrm{U} 428$ & 0.026 & 0.025 & 0.058 & 0.084 & 0.052 & 0 . & T) & 0.19 & 等 & -0.036 & -0.024 & -0.022 & -0.106 & -0.174 & -0.362 & 72 & 0.48 \\
\hline U386 & 0.023 & 0.015 & 0.041 & 0.014 & 0.007 & 0.100 & 20 & -0.20 & (3) & -0.007 & 0.052 & 0.036 & -0.089 & -0.276 & -0.285 & 57 & - \\
\hline U029 & 0.003 & 0.023 & 0.027 & 0.026 & 0.011 & 0.090 & 0.018 & 0.36 & U349 & -0.024 & -0.019 & -0.018 & -0.063 & -0.064 & 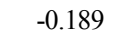 & .038 & 0.28 \\
\hline $\mathrm{U} 430$ & 0.015 & 0.033 & 0.040 & 0.006 & -0.008 & 0.086 & 0.017 & - & U379 & -0.022 & -0.029 & -0.026 & -0.042 & -0.065 & 34 & .037 & 0.31 \\
\hline U353 & 0.012 & 0.026 & 0.022 & 0.014 & 0.009 & 0.082 & 0.016 & -0.09 & U709 & -0.007 & -0.005 & -0.003 & -0.054 & -0.111 & 80 & .036 & 0.97 \\
\hline U219 & 0.001 & 0.032 & 0.024 & 0.010 & 0.004 & 0.072 & 0.014 & 0.33 & U365 & -0.023 & -0.025 & 0.013 & -0.040 & -0.088 & 162 & .032 & - \\
\hline U002 & 0.016 & 0.026 & 0.013 & 0.014 & -0.002 & 0.067 & 13 & - & U313 & -0.024 & -0.004 & 0.007 & -0.045 & -0.085 & -0.150 & .030 & - \\
\hline U250 & 0.003 & 0.004 & 0.037 & 0.034 & -0.011 & 0.0 & 0.013 & - & U707 & -0.031 & -0.051 & -0.032 & -0.023 & -0.003 & $=0140$ & 288 & -0.44 \\
\hline U514 & 0.009 & 0.001 & 0.011 & 0.020 & 0.025 & 0. & 0.013 & 0.28 & U327 & -0.010 & -0.013 & -0.020 & -0.039 & -0.055 & & 27 & 53 \\
\hline U360 & 0.007 & 0.026 & .050 & .007 & -0.012 & 0.064 & & 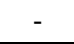 & U375 & -0.072 & -0.057 & -0.032 & 0.002 & 0.0 & & & - \\
\hline U424 & .010 & 0.005 & 017 & 0.006 & 0.022 & 0.060 & & 0.23 & נונה & 0.015 & -0.005 & -0.020 & -0.053 & -0.059 & & & - \\
\hline U700 & 0.009 & 0.010 & .008 & 0.013 & 0.012 & 0.053 & 11 & 0.0 & 362 & -0.008 & -0.012 & 0.009 & -0.023 & -0.077 & -0.111 & 22 & - \\
\hline U345 & -0.011 & -0.003 & 0.044 & 0.024 & -0.001 & 0.053 & 011 & - & 427 & -0.030 & -0.015 & -0.003 & -0.015 & -0.045 & -0.1 & 022 & 0.11 \\
\hline U701 & -0.007 & 0.005 & 0.015 & 0.014 & 0.025 & 0.052 & 0.010 & - & U526 & -0.047 & -0.013 & -0.004 & -0.023 & -0.012 & -0.098 & -0.020 & -0.29 \\
\hline U720 & 0.009 & 0.017 & 0.019 & -0.001 & -0.001 & 0.043 & 0.009 & - & U548 & -0.018 & -0.011 & -0.015 & -0.023 & -0.022 & -0.090 & -0.018 & 0.06 \\
\hline U429 & 0.004 & -0.001 & 0.015 & 0.014 & 0.006 & 0.039 & 0.008 & - & U715 & 0.001 & 0.000 & 0.013 & -0.016 & -0.084 & -0.0 & -0.017 & - \\
\hline U062 & 0.002 & 0.011 & 0.009 & 0.015 & -0.003 & 0.03 & 77 & - & $\mathrm{U}$ & -0.015 & -0.047 & 0.035 & 0.027 & -0.073 & -6 & 015 & - \\
\hline U341 & 0.002 & 0.008 & 0.012 & 0.011 & -0.001 & . & 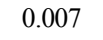 & - & 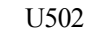 & -0.028 & -0 . & -0.008 & -0.005 & -0.018 & -0.071 & 14 & -0.11 \\
\hline U034 & -0.002 & 0.001 & 0.003 & 0.003 & 0.021 & 0. & & - & 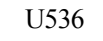 & -0.016 & -0.014 & -0.008 & -0.015 & -0.018 & 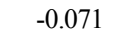 & 14 & T.0. \\
\hline U008 & 0.002 & 0.002 & 0.009 & 0.008 & 0.005 & & & 0.1 & 列 & -0.034 & -0.006 & -0.002 & -0.004 & -0.023 & & 14 & -0.10 \\
\hline U702 & 0.005 & 0.011 & 0.004 & -0.004 & 0.004 & 0.020 & & - & U525 & 44 & 15 & -0.003 & -( & -0 & & 14 & 11 \\
\hline U800 & 0.003 & 0.004 & 0.004 & 0.003 & 0.005 & 0. & 0.004 & 0.1 & 8 & -0.012 & -0.017 & -0.007 & -0.014 & -0.015 & -0 & 13 & 0.05 \\
\hline U252 & -0.014 & -0.013 & 0.005 & -0.002 & 0.041 & 0.017 & 0.003 & - & U359 & 0.001 & -0.006 & 0.002 & -0.026 & -0.032 & -0.062 & -0.012 & - \\
\hline U396 & -0.002 & -0.002 & 0.009 & 0.015 & -0.003 & 0.017 & 0.003 & - & U725 & 0.003 & -0.002 & -0.006 & -0.016 & -0.040 & -0.061 & -0.012 & - \\
\hline U095 & 0.005 & 0.003 & 0.002 & 0.000 & 0.004 & 0.013 & 0 & - & U340 & -0.007 & -0.013 & -0.004 & -0.015 & -0.021 & $-0.05 \mathrm{C}$ & -0.012 & 0.33 \\
\hline U716 & 0.003 & -0.002 & -0.001 & 0.007 & 0.006 & 0. & 0.003 & - & $\mathrm{U}$ & -0.012 & -0.004 & -0.006 & -0.016 & -0.020 & -0 & 12 & .13 \\
\hline U385 & -0.008 & 0 & 0.018 & 0.004 & -0. & 0 & 0.002 & - & U544 & -0.014 & -0.004 & -0.006 & -0.013 & -0.020 & 1 & 11 & 0.09 \\
\hline U075 & 0.005 & -0.001 & 0.002 & 0.001 & 0.002 & 0008 & 0.002 & - & U52? & -0.010 & 0.001 & -0.002 & 0.004 & -0.049 & . & 11 & - \\
\hline btotal & 526 & 0.765 & 560 & 0.691 & 0.224 & 3.766 & - & - & total & -1.729 & -1.573 & -1.219 & -1.978 & -2.957 & 9.457 & - & - \\
\hline
\end{tabular}

*: the average rate of increase by geometric mean.

had positive rates of increase. This increasing trend in major technology areas with negative DCEs is contrasted with the decreasing trend in major areas with positive DCEs. Overall, the subtotal of the top 30 technology areas with positive DCEs increased until the period 2007-2008 but then decreased, while the subtotal of the top 30 technology areas with negative DCEs decreased steadily during all periods. Moreover, absolute values of subtotals over time for the top 30 areas with negative DCEs were larger than those in the top 30 areas with positive DCEs. This indicates that many dominant technology areas in Korea are gradually changing to absorb and internalize external technological knowledge.

\subsection{Mapping Evolving Trajectories of Technology Areas}

Technological impacts and DCEs of technology areas within the whole Korean technology system were individually analyzed in the previous subsection. Based on those results, we see that visualization considering both of the chosen technological characteristics improve understanding of evolving technology trajectories over time. Furthermore, TRMs obtained by using DEMATEL include impact relationships between all pairs of technology areas, so adjacent technology areas with strong relationships can be identified. As a case study, we ob- 
serve the dynamic trajectories and impact relationships during the five chosen time periods for several interesting technology areas, including U257, U438, U455, and U375 (pulse or digital communications) (Figure 2 and Table 5); similarly, it is possible for analysts to choose any set of technology areas. From the change in trajectories over time, the overall technological impacts of the four areas increased, while the changes in their DCE values were diverse.

The results above show that $\mathrm{U} 257$ had the strongest technological impact and DCE, with an interesting trajectory. We consider U257 to be a typical application technology area because it mostly received technological knowledge from external sources during all time periods. U257 did not experience a significant change in technological impact during the first three time periods but showed a rapidly increasing pattern during the last two periods. As the patent registration in that area increased, it seems that the technological impact of U257 also increased. This trajectory also suggests that, during periods 2009-2010 and 2011-2012, Korean applicants tried to develop various technologies and products compatible with solid-state memory and transistor devices based on existing technological knowledge. From the analysis of impact relationships, we found that U257 had active relationships with U438, U349 (liquid crystal cells, elements, and systems), and U365; providing most of its technological knowledge to U438 and U349 and U365 and U977 (nanotechnology), and receiving external knowledge from U438, U349, U365, and U428.

U438 also showed a distinguishing trend in its trajectory. U438's technological impact increased over time, but its DCE had an increasing pattern until the period 2007-2008, after which it decreased rapidly. During the final period, 2011-2012, U438 still had a very strong technological impact, but its DCE was very close to 0 . This indicates that the semiconductor manufacturing process technology was an original technology, which

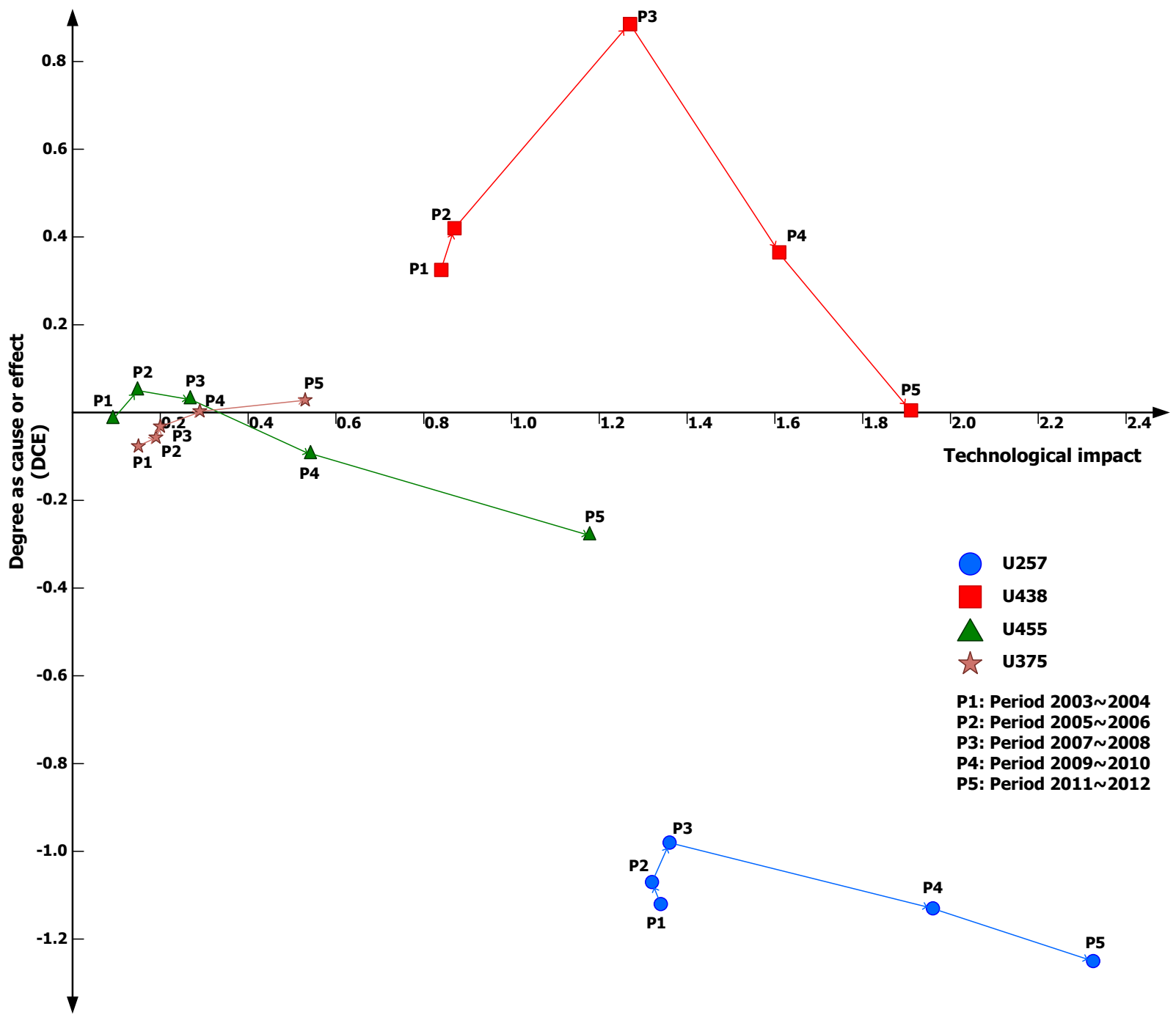

Figure 2. Trajectories of selected technology areas. 
mostly provided other areas with technological knowledge, until 2008 but was rapidly changing to both actively diffuse its technological knowledge to external recipients and absorb external technological knowledge. Regarding impact relationships, U438 showed an active knowledge exchange relationship with U257, U349, and U216 (substrate etching processes); U438 provided technological knowledge mostly to those three technology areas and received most of its external knowledge from the same three areas.

The technological impacts and DCEs of U455 and U375 were not stronger than those of U257 and U438, but they had a distinctive feature in their change in DCE value. The trajectory of U455 had a knowledge-receiving pattern (weak negative DCE) during period 20032004 , then started to increase the provision of its technological knowledge to external recipients (positive DCE) during periods 2005-2006 and 2007-2008, and finally transformed rapidly toward mostly receiving external technological knowledge (strong technological impact and DCE) during periods 2009-2010 and 2011-2012. This trajectory explains that the telecommunication technology area was not a major technology area in Korea until 2007 or 2008, but after that, it began to incorporate other technology areas and recently matured as a dominant and influential application area within the Korean technology system. According to the analysis of impact relationships, it seems that $\mathrm{U} 455$ provided its knowledge to U370, U379 (telephonic communications), and U375, and mostly received external technological knowledge from U370, U375, and U348. Next, U375 showed a gradual increase in technological impact and DCE, although the values were smaller than those of the other three technology areas. U375 also showed an in-

Table 5. Impact relationships of selected technology areas

\begin{tabular}{|c|c|c|c|c|c|c|c|c|c|c|}
\hline \multirow[b]{3}{*}{ Rank } & \multicolumn{10}{|c|}{ U257 } \\
\hline & \multicolumn{2}{|c|}{ 2003-2004 } & \multicolumn{2}{|c|}{$2005-2006$} & \multicolumn{2}{|c|}{$2007-2008$} & \multicolumn{2}{|c|}{$2009-2010$} & \multicolumn{2}{|c|}{$2011-2012$} \\
\hline & Outward & Inward & Outward & Inward & Outward & Inward & Outward & Inward & Outward & Inward \\
\hline 1 & U438 & U438 & U438 & U438 & U438 & U438 & U438 & U438 & U438 & U438 \\
\hline 2 & U349 & U349 & U349 & U349 & U349 & U349 & U349 & U428 & U349 & U349 \\
\hline 3 & U365 & U365 & U365 & U365 & U365 & U365 & U977 & U349 & U977 & U428 \\
\hline 4 & U977 & U250 & U977 & U430 & U361 & U428 & U365 & U365 & U365 & U313 \\
\hline \multirow[t]{3}{*}{5} & U361 & U430 & U361 & U361 & U313 & U250 & U313 & U313 & U313 & U365 \\
\hline & \multicolumn{10}{|c|}{ U438 } \\
\hline & \multicolumn{2}{|c|}{ 2003-2004 } & \multicolumn{2}{|c|}{$2005-2006$} & \multicolumn{2}{|c|}{$2007-2008$} & \multicolumn{2}{|c|}{$2009-2010$} & \multicolumn{2}{|c|}{$2011-2012$} \\
\hline Rank & Outward & Inward & Outward & Inward & Outward & Inward & Outward & Inward & Outward & Inward \\
\hline 1 & U257 & U257 & U257 & U257 & U257 & U257 & U257 & U257 & U257 & U257 \\
\hline 2 & U430 & U349 & U349 & U349 & U349 & U216 & U349 & U349 & U977 & U216 \\
\hline 3 & U349 & U216 & U365 & U029 & U216 & U349 & U977 & U216 & U349 & U349 \\
\hline 4 & U427 & U427 & U216 & U216 & U977 & U250 & U216 & U365 & U365 & U174 \\
\hline \multirow[t]{3}{*}{5} & U216 & U430 & U977 & U430 & U365 & U365 & U365 & U250 & U313 & U313 \\
\hline & \multicolumn{10}{|c|}{ U455 } \\
\hline & \multicolumn{2}{|c|}{$2003-2004$} & \multicolumn{2}{|c|}{$2005-2006$} & \multicolumn{2}{|c|}{$2007-2008$} & \multicolumn{2}{|c|}{$2009-2010$} & \multicolumn{2}{|c|}{$2011-2012$} \\
\hline Rank & Outward & Inward & Outward & Inward & Outward & Inward & Outward & Inward & Outward & Inward \\
\hline 1 & U370 & U370 & U370 & U370 & U370 & U370 & U370 & U370 & U370 & U370 \\
\hline 2 & U379 & U375 & U379 & U375 & U379 & U375 & U379 & U375 & U375 & U375 \\
\hline 3 & U375 & U348 & U375 & U379 & U375 & U348 & U375 & U379 & U379 & U725 \\
\hline 4 & U330 & U379 & U343 & U348 & U348 & U398 & U709 & U340 & U345 & U709 \\
\hline \multirow[t]{3}{*}{5} & U348 & U340 & U348 & U343 & U342 & U235 & U725 & U348 & U709 & U379 \\
\hline & \multicolumn{10}{|c|}{$\mathrm{U} 375$} \\
\hline & \multicolumn{2}{|c|}{ 2003-2004 } & \multicolumn{2}{|c|}{ 2005-2006 } & \multicolumn{2}{|c|}{$2007-2008$} & \multicolumn{2}{|c|}{ 2009-2010 } & \multicolumn{2}{|c|}{ 2011-2012 } \\
\hline Rank & Outward & Inward & Outward & Inward & Outward & Inward & Outward & Inward & Outward & Inward \\
\hline 1 & U348 & U382 & U348 & U370 & U455 & U382 & U370 & U370 & U455 & U370 \\
\hline 2 & U370 & U370 & U370 & U382 & U370 & U370 & U455 & U455 & U370 & U455 \\
\hline 3 & U382 & U348 & U382 & U455 & U348 & U455 & U348 & U382 & U348 & U382 \\
\hline 4 & U386 & U386 & U455 & U348 & U714 & U341 & U327 & U714 & U382 & U725 \\
\hline 5 & U714 & U455 & U714 & U341 & U382 & U348 & U382 & U341 & U714 & U714 \\
\hline
\end{tabular}


teresting trajectory over time. It started with a negative DCE during the first three periods but began to show a tendency to provide technological knowledge during the last two periods. In particular, its technological impact rapidly increased during the last period. U375, in fact, is a technology area related to network data transfer and control. Taking into consideration this increasing trend of U375's technological impact and DCE values, network data transfer and control technology has the potential to be an increasingly influential technology area for mobile and wireless industries in Korea. Considering impact relationships, we found that U375 recently provided its technological knowledge to U455, U370, U382 (image analysis), and U348 and received external knowledge primarily from areas U370, U455, U714 (error detection/correction and fault detection/recovery), and U348.

\section{DISCUSSION AND CONCLUSIONS}

In this study, we analyzed technological characteristics, particularly technological impacts and DCEs, of technology areas within the Korean technology system and observed their dynamic trends. To this end, we employed two network analysis methods: patent coclassification and DEMATEL. Patent co-classification analysis was used to construct directed TKF matrices among technology areas that represent the whole technology system in Korea. Patent co-classification analysis uses patent classification codes instead of using citations between pairs of patents. Patent co-classification uses the relationships of a patent with a primary USPC class and supplementary USPC classes, and these relationships are conceptualized as the TKFs; classification codes of patents are assigned at the date of patent registration and are not affected by the time lag that exists in the citation relationship between patents. Therefore, patent co-classification analysis has the advantage that it can identify TKFs among various technology areas when dealing with the most recent patents. In our analysis, $32.81 \%$ of patent data were registered during 2011 2012, giving them little chance to be cited by other later patents. In this regard, the patent co-classification approach can be a good alternative to the patent citation approach and, moreover, will help generate a method for R\&D planners to analyze the most recent technological trends in patent data.

To determine the comprehensive impact among technology areas, this study employed DEMATEL. Although many technology network-based studies have been previously suggested, they used only direct knowledge spillover and impacts among technology areas. This study has the advantage that it can capture both direct and indirect impacts among technology areas in order to measure the overall impact. To do so, we quantified the customary DEMATEL process and incorporated it into patent analysis. In addition, we modified
DEMATEL to observe and compare dynamic trends and trajectories over time (Section 4.2). Therefore, our modified DEMATEL approach enables analysts to more comprehensively identify technological impacts, DCEs of technology areas and their evolving patterns within a technology network.

Using large-scale patent data, we explained the working mechanism of our approach that incorporates patent co-classification and DEMATEL and showed the approach's potential applicability to identifying interacting relationships among various technology areas. In this research, we analyzed the technological knowledge impacts of technology areas that constitute the whole technology system of Korea, by exploiting all patents registered during 2003-2012. In particular, we determined the technological impacts and DCEs of technology areas over time, thereby observing the evolving trajectories and impact relationships. From an overall perspective, the technological impact of each technology area in Korea has increased steadily over time. Interestingly, the total technological impact of the top 30 technology areas, which can be considered the dominant and mainstream areas in Korea, increased from $63.79 \%$ to $70.67 \%$ over the examined time period. This finding shows that technological advances and influences in Korea have been concentrated in specific high-technology areas in industries including semiconductors, mobile phones, and communication. This industrial concentration in one hand indicates Korean national R\&D obtains excellent results in such major high-technology areas, but on the other hand there should be considerations about diversified R\&D planning encompassing other technology areas, such as medical and healthcare technologies. Another interesting finding is that many of these dominant technology areas began to change to receive more external technological knowledge during the last ten years; $50 \%$ of the top 30 technology areas with negative DCE values had positive rates of increase. This change suggests that these technologies are intended to create values by incorporating other technologies; we believe this tendency stems from the Korean national policy that has put emphasis on convergence technologies at the beginning of the 21 st century. Therefore, it is needed that national R\&D policy makers should develop business development programs to commercialize the R\&D outputs. One contribution of this study is that the analysis results are a useful data source that can be directly used in the process of R\&D planning at the national level. Moreover, our method has the potential to be applicable for any other patent data at the national or industry level, although this study applied the method only to Korean applicant patent data registered during the last ten years. Therefore, with the aid of the proposed method, R\&D planners in industry and government will be able to identify the evolving trends of technological impacts and interactions among various technologies by exploiting patent data that fit specific analysis purposes. 
Despite the study's contributions, challenging tasks remain to be further considered, so we conclude the paper with implications for several future research topics. First, in this paper, we only used patent co-classification analysis as an alternative to patent citation analysis. In fact, these two analysis methods each have their pros and cons, so incorporating them into a combined method or comparing the results from the two methods would be an interesting future research topic. Second, this research divided ten years into five time periods. For broader and more detailed analysis, further research could extend the time range for patent collection and consider different periods such as ten (yearly) or 20 (half-yearly) time periods. Third, this study analyzed Korean patents in the USPTO database. Our analysis approach is fundamentally applicable to any other nation's patent set. Therefore, a possible future research topic would be to observe technological impacts and DCEs of technology areas within other countries' technology systems and to conduct international comparisons. This could help determine distinguishing features of technological advances in the studied countries, thereby delivering significant implications for R\&D planners. Finally, this study used historical data, that is, patent registrations. Using techniques to forecast TKFs among technology areas would be a good topic to further develop this research.

\section{REFERENCES}

Almus, M. and Czarnitzki, D. (2003), The effects of public R\&D subsidies on firms' innovation activities: the case of Eastern Germany, Journal of Business \& Economic Statistics, 21(2), 226-236.

Breschi, S. And Lissoni, F. et al. (2003), Knowledgerelatedness in firm technological diversification, Research Policy, 32(1), 69-87.

Chen, Y.-H. and Chen, C.-Y. et al. (2011), Technology forecasting and patent strategy of hydrogen energy and fuel cell technologies, International Journal of Hydrogen Energy, 36(12), 6957-6969.

Cho, T.-S. and Shih, H.-Y. (2011), Patent citation network analysis of core and emerging technologies in Taiwan: 1997-2008, Scientometrics, 89(3), 795-811.

Choi, S. and Yoon, J. et al. (2011), SAO network analysis of patents for technology trends identification: a case study of polymer electrolyte membrane technology in proton exchange membrane fuel cells, Scientometrics, 88(3), 863-883.

Fontela, E. and Gabus, A. (1976), The DEMATEL observer, Battelle Institute, Geneva Research Center.

Foray, D. and Mowery, D. et al. (2012), Public R\&D and social challenges: What lessons from mission R\&D programs? Research Policy.

Gabus, A. and Fontela, E. (1972), World problems, an invitation to further thought within the framework of DEMATEL, Battelle Geneva Research Center, Geneva, Switzerland.

Garcia, A. and Mohnen, P. A. (2010), Impact of government support on R\&D and innovation, UNU-MERIT, Maastricht Economic and Social Research and Training Centre on Innovation and Technology.

Han, Y.-J. and Park, Y. (2006), Patent network analysis of inter-industrial knowledge flows: The case of Korea between traditional and emerging industries, World Patent Information, 28(3), 235-247.

Hanneman, R. A. and Riddle, M. (2001), Social network analysis, Riverside: University of California.

Haythornthwaite, C. (1996), Social network analysis: An approach and technique for the study of information exchange, Library and Information Science Research, 18(4), 323-342.

Hsu, C.-W. and Kuo, T.-C. et al. (2011), Using DEMATEL to develop a carbon management model of supplier selection in green supply chain management, Journal of Cleaner Production.

Huang, C. and Su, J. et al. (2011), Government funded renewable energy innovation in China, Energy Policy.

Inzelt, A. (2004), The evolution of university-industrygovernment relationships during transition, Research Policy, 33(6), 975-995.

Jafie, A. B. and Trajtenberg, M. et al. (2000), Knowledge Spillovers and Patent Citations: Evdence from a Survey of Inventors, NBER/Sloan, 21.

Jeong, S. and Yang, J. et al. (2012), Analysis of technology spillover using patent citation database: application of DEMATEL, Entrue Journal of Information Technology, 11(1), 111-124.

Kim, E. and Cho, Y. et al. (2013), Dynamic patterns of technological convergence in printed electronics technologies: patent citation network, Scientometrics, 1-24.

Ko, N. and Yoon, J. et al. (2013), Analyzing interdisciplinarity of technology fusion using knowledge flows of patents, Expert Systems with Applications.

Lee, H.-J. and Lee, S. et al. (2011), Technology clustering based on evolutionary patterns: The case of information and communications technologies, $\mathrm{Te}$ chnological Forecasting and Social Change, 78(6), 953-967.

Lee, H. and Kim, C. et al. (2009), An ANP-based technology network for identification of core technologies: A case of telecommunication technologies, Expert Systems with Applications, 36(1), 894-908.

Lee, P.-C. and Su, H.-N. et al. (2010), Quantitative mapping of patented technology-The case of electrical conducting polymer nanocomposite, Technological Forecasting and Social Change, 77(3), 466478.

Lee, S. and Yoon, B. et al. (2009), Business planning 
based on technological capabilities: Patent analysis for technology-driven roadmapping, Technological Forecasting and Social Change, 76(6), 769-786.

Lee, S. and Yoon, B. et al. (2009), An approach to discovering new technology opportunities: Keyword-based patent map approach, Technovation, 29(6), 481-497.

Li, X. and Chen, H. et al. (2007), Patent citation network in nanotechnology (1976-2004), Journal of Nanoparticle Research, 9(3), 337-352.

Lim, H. and Park, Y. (2010), Identification of technological knowledge intermediaries, Scientometrics, 84(3), 543-561.

Lin, R.-J. (2011), Using fuzzy DEMATEL to evaluate the green supply chain management practices, $J_{o}$ urnal of Cleaner Production.

Mamuneas, T. P. and Ishaq Nadiri, M. (1996), Public $\mathrm{R} \& \mathrm{D}$ policies and cost behavior of the US manufacturing industries, Journal of Public Economics, 63(1), 57-81.

Maurseth, P. B. and Verspagen, B. (2002), Knowledge spillovers in Europe: a patent citations analysis, The Scandinavian Journal of Economics, 104(4), 531-545.

No, H. J. and Park, Y. (2010), Trajectory patterns of technology fusion: Trend analysis and taxonomical grouping in nanobiotechnology, Technological Forecasting and Social Change, 77(1), 63-75.

Nomaler, Ö. and Verspagen, B. (2008), Knowledge flows, patent citations and the impact of science on technology, Economic Systems Research, 20(4), 339-366.

Park, H., Kim, K. et al. (2012), A Patent intelligence system for strategic technology planning, Expert Systems with Applications.

Park, H. and Yoon, J. (2013), Assessing coreness and intermediarity of technology sectors using patent co-classification analysis: the case of Korean national R\&D. Scientometrics, 1-38.

Park, J. and Lee, H. et al. (2009), Disembodied knowledge flows among industrial clusters: A patent analysis of the Korean manufacturing sector, Tech- nology in Society, 31(1), 73-84.

Saaty, T. L. (2001), The analytic network process: decision making with dependence and feedback, RWS Publ.

Saaty, T. L. (2004), Fundamentals of the analytic network process-Dependence and feedback in decision-making with a single network, Journal of Systems Science and Systems Engineering, 13(2), 129157.

Shen, Y.-C. and Lin, G. T. et al. (2011), Combined DEMATEL techniques with novel MCDM for the organic light emitting diode technology selection, Expert Systems with Applications, 38(3), 1468-1481.

Shieh, J.-I., Wu, H.-H. et al. (2010), A DEMATEL method in identifying key success factors of hospital service quality, Knowledge-Based Systems, 23(3), 277-282.

Tseng, M.-L. (2009), A causal and effect decision making model of service quality expectation using greyfuzzy DEMATEL approach, Expert Systems with Applications, 36(4), 7738-7748.

Verspagen, B. (1997), Measuring intersectoral technology spillovers: estimates from the European and US patent office databases, Economic Systems Research, 9(1), 47-65.

Wang, T.-Y., Chien, S.-C. et al. (2007), The role of technology development in national competitiveness-Evidence from Southeast Asian countries, $\mathrm{Te}$ chnological Forecasting and Social Change, 74(8), 1357-1373.

Wu, W.-W. (2008), Choosing knowledge management strategies by using a combined ANP and DEMATEL approach, Expert Systems with Applications, 35(3), 828-835.

Yoon, B. and Park, Y. (2004), A text-mining-based patent network: Analytical tool for high-technology trend, The Journal of High Technology Management Research, 15(1), 37-50.

Yoon, J. and Kim, K. (2011), Identifying rapidly evolving technological trends for R\&D planning using SAO-based semantic patent networks, Scientometrics, 88(1), 213-228. 